\title{
Recurrent myocardial infarctions in a young football player secondary to thrombophilia, associated with elevated factor VIII activity
}

This article was published in the following Dove Press journal:

International Medical Case Reports Journal

31 October 2014

Number of times this article has been viewed

\section{Thomas PVacek \\ Shipeng Yu \\ Shahnaz Rehman \\ Blair P Grubb \\ Daniel Kosinski \\ Cherian Verghese \\ Ehab A Eltahawy \\ Qaiser Shafiq}

Department of Medicine, University of Toledo Medical Center,Toledo, $\mathrm{OH}$, USA
Correspondence: TP Vacek Department of Medicine, University of Toledo Medical Center, 3000 Arlington Ave, Toledo, $\mathrm{OH}$ 43614, USA

Email tpvace0I@gmail.com
Abstract: Myocardial infarction (MI) due to coronary atherosclerosis in young adults is uncommon; rare causes such as cocaine abuse, arterial dissection, and thromboembolism should be considered. A 21-year-old football player, and otherwise healthy African American man, developed chest pain during exercise while bench-pressing $400 \mathrm{lbs}$. Acute MI was diagnosed based on physical examination, electrocardiography findings, and elevated cardiac enzymes. Coronary arteriography showed a thrombus occluding the proximal left anterior descending artery (LAD). Aggressive antiplatelet therapy with aspirin, clopidogrel, and eptifibatide was pursued, in addition to standard post-MI care. This led to the successful resolution of symptoms and dissolution of the thrombus, demonstrated by repeat coronary arteriography. Five months later, he presented with similar symptoms during exercise after lifting heavy weights, and was found to have another acute MI. Coronary arteriography again showed a thrombus occluding the LAD. No evidence of coronary artery dissection or vasospasm was found. Only mild atherosclerotic plaque burden was observed on both occasions by intravascular ultrasound. A bare metal stent was placed at the site as it was thought this site had acted as a nidus for small plaque rupture and thrombus formation. Elevated serum factor VIII activity at 205\% (reference range $60 \%-140 \%$ ) was found, a rare cause of hypercoagulability. Further workup revealed a patent foramen ovale during a Valsalva maneuver by transesophageal echocardiography. Both events occurred during weight lifting, which can transiently increase right heart pressure in a similar way to the Valsalva maneuver. In light of all the findings, we concluded that an exercise-related increase in factor VIII activity led to coronary arterial thrombosis in the presence of a small ruptured plaque. Alternatively, venous clots may have traversed the patent foramen ovale and occluded the LAD. In addition to continuing aggressive risk factor modification, anticoagulation therapy with warfarin was initiated with close follow-up.

Keywords: MI, factor VIII, exercise, myocardial infarction, young, football player

\section{Introduction}

Myocardial infarction (MI) in young adults is rare and only accounts for 3\% of coronary heart disease cases; classification falls under atheromatous, nonatheromatous, substance abuse, and hypercoagulable states. ${ }^{1}$ There are documented cases of early MI from atherosclerosis secondary to dyslipidemia, obesity, diabetes, smoking, and hyperhomocysteinemia; however, these cases generally occur in patients in their mid-30s at the earliest. ${ }^{2}$

Alternatively, perhaps there is a nonatheromatous process occurring. The patient could have some coronary dissection or compression from previous trauma to the chest in light of a high-impact sport such as football. This has been documented in patients 
involved in motor vehicle accidents with blunt trauma to the chest. ${ }^{3-5}$ Perhaps there is a bridging of coronary vessels within actual myocardial tissue that becomes compressed during activity. Maybe there is an anomalous origin of the coronary arteries, resulting in chronic intermittent ischemia and leading to scarring and death with typical chest pain symptoms. Certainly, intense activity such as weight lifting may exacerbate such a condition. ${ }^{6}$

Moreover, drug use and septic embolism, cocaine, amphetamines, tetrahydrocannabinol (THC), and binge drinking are known to precipitate these events via vasospasm, arrhythmia, and vessel rupture. ${ }^{7}$ This is one of the more common causes of MI in young adults engaging in risky behaviors that include drug abuse. The final category, hypercoagulable state, is a feature of this case and will be discussed subsequently. ${ }^{8-10}$

\section{Case presentation}

A healthy 21-year-old male African American college football player, with a body mass index (BMI) of 39 and no additional risk factors for coronary artery disease, was admitted to the emergency department. The patient was complaining of a single episode of unrelenting sharp chest pain immediately after he had finished powerlifting 400 lbs in a bench press lift. The chest pain was largely typical: substernal, associated with shortness of breath, exertional, constant, and not musculoskeletal in nature.

The patient reported no known drug allergies and took no medications or supplements. He had no chronic medical problems and both parents were alive without chronic medical problems. There was no history of deep venous thrombosis (DVT), pulmonary embolism, or coronary heart disease in the family. A review of systems was only positive for the above. His vital statistics on admission were within normal limits. The physical exam was largely benign.

Imaging results obtained included chest radiography that only showed cardiomegaly, consistent with an athletic heart. An electrocardiogram showed a sinus rhythm with a right bundle branch block (RBBB) (Figure 1). A urine toxicity screen was negative for cocaine and central nervous system stimulants. The lipid profile was within normal limits. At the emergency room, blood tests showed elevated serum levels of cardiac enzymes, with troponin at a level of 0.53 , which peaked at 10.43 the next day (Table 1). Non-ST elevation myocardial infarction was diagnosed and the patient received medical treatment as per acute coronary syndrome protocol, which includes aspirin, a statin, a high intensity intravenous heparin protocol, an angiotensin converting enzyme (ACE) inhibitor, and a beta blocker.

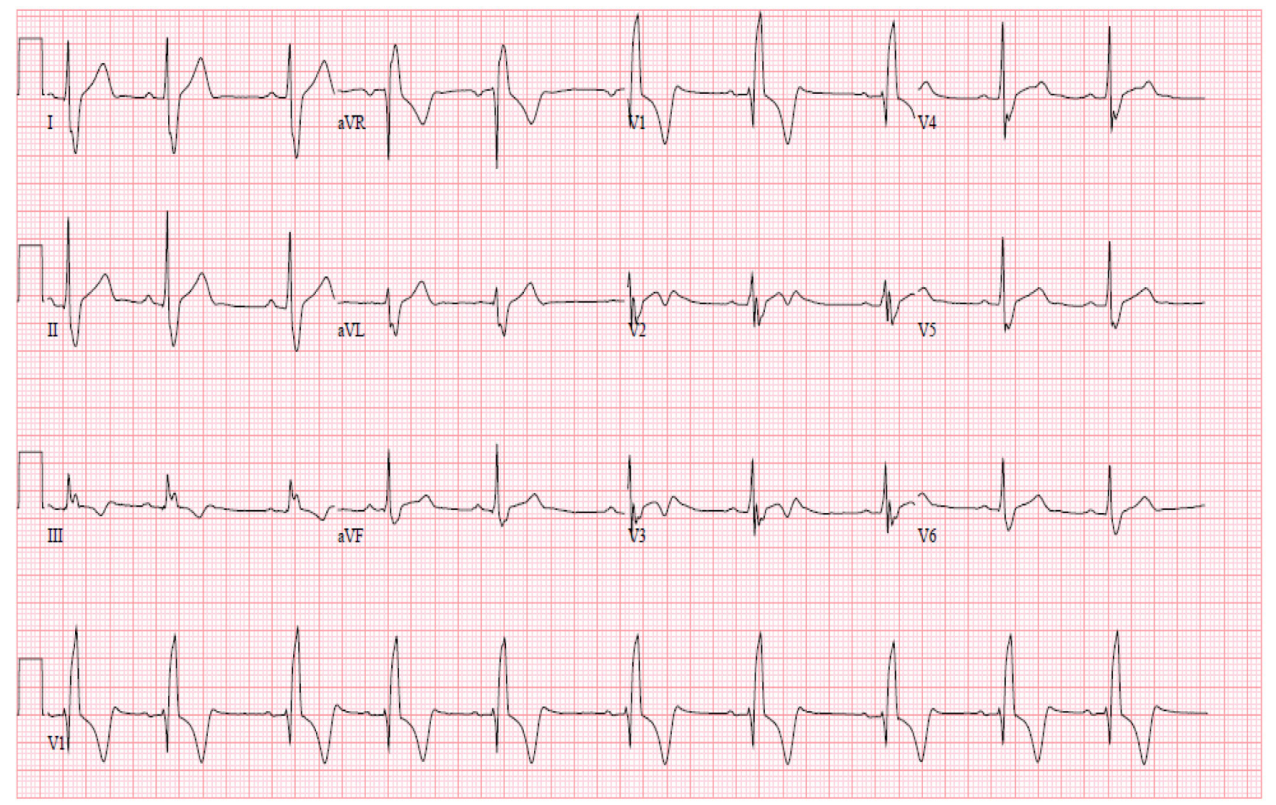

Normal sinus with sinus arrhythmia, RBBB

Figure I EKG initial presentation.

Note: An EKG showed a sinus rhythm with a right bundle branch block (RBBB) but without signs of ischemia.

Abbreviation: EKG, electrocardiogram. 
Table I Cardiac enzymes

\begin{tabular}{|c|c|c|c|c|c|c|}
\hline & Marker and range & Day of admission & 6 hours & I 2 hours & 21 hours & 30 hours \\
\hline \multirow[t]{5}{*}{ First event } & Troponin (0-0.04) & 0.53 & 8.28 & 10.43 & 8.67 & 7.57 \\
\hline & Myoglobin (0-90) & 412 & 97 & - & - & - \\
\hline & CK-MB (0.0-5.0) & II.I & 46.1 & 53.4 & 43.8 & 26.1 \\
\hline & CK (15-200) & 789 & 1,215 & $\mathrm{I}, 442$ & $\mathrm{I}, 094$ & 828 \\
\hline & Marker and range & Day of admission & 3 hours & 6 hours & I4 hours & 41 hours \\
\hline \multirow[t]{4}{*}{ Second event } & Troponin (0-0.04) & 0.08 & 0.39 & 1.06 & $\mathrm{I} .74$ & 1.96 \\
\hline & Myoglobin (0-90) & 133 & 100 & 98 & 31 & 35 \\
\hline & CK-MB (0.0-5.0) & 3.3 & 5.2 & 7.6 & 11.4 & 12.1 \\
\hline & CK (I5-200) & 444 & 423 & 472 & 47I & 358 \\
\hline
\end{tabular}

Notes: Blood tests showed elevated serum levels of cardiac enzymes, with troponin at a level of 0.53 , which peaked at 10.43 the next day. Abbreviation: CK-MB, creatine kinase-MB.

Transthoracic echocardiography (TTE) was performed in the emergency room and was unremarkable. A computerized tomography (CT) angiogram of the chest was negative for aortic dissection. A transesophageal echocardiogram (TEE) showed a very minor patent foramen ovale (PFO) only with a Valsalva maneuver and was not apparent on a Doppler view (Figure 2A). During the Valsalva maneuver, a single bubble became apparent (Figure 2B). There was no aortic dissection. A coronary angiography showed a thrombus in the proximal to mid left anterior descending artery (LAD) in otherwise normal coronary arteries (Figure 3). Intravascular ultrasound showed evidence of thrombotic material in the mid LAD in addition to mild plaque disease, and no evidence of dissection in the left main, proximal, or mid LAD (Figure 4). The patient received Integrilin ${ }^{\circledR}$ after coronary angiography. One week after the onset of chest pain, another coronary angiography showed resolution of the LAD thrombus (Figure 3). The patient was then discharged with aspirin ( $81 \mathrm{mg}$ daily), clopidogrel (75 mg daily), and atorvastatin ( $80 \mathrm{mg}$ daily), with advice to avoid strenuous activities such as heavy weight lifting. The patient received six sessions in the cardiopulmonary rehabilitation program before volitional discontinuation.

Five months later, the patient had another episode of chest pain after heavy weight lifting. This episode was similar to the last, but had less intense, substernal nonradiating pressure without shortness of breath or lightheadedness. Pain was relieved with aspirin, nitroglycerin, and morphine. His vital statistics on admission this time showed some stage II hypertension.

He admitted not taking his medication for several days to a week before this episode of chest pain. The physical exam was again benign. Cardiac enzymes were elevated, with electrocardiography showing marked sinus bradycardia with PAC and existing $\mathrm{T}$ wave inversions in the inferior leads (Table 1 and Figure 5). The patient had a coronary angiography on the day of symptom onset. A thrombus was again found in the mid LAD, but was longer than the thrombus found 5 months previously. It was thought that this site had provided a nidus for thrombus formation via recurrent plaque rupture and previous vessel injury. Hence, a bare metal stent was placed on this occasion, as the patient
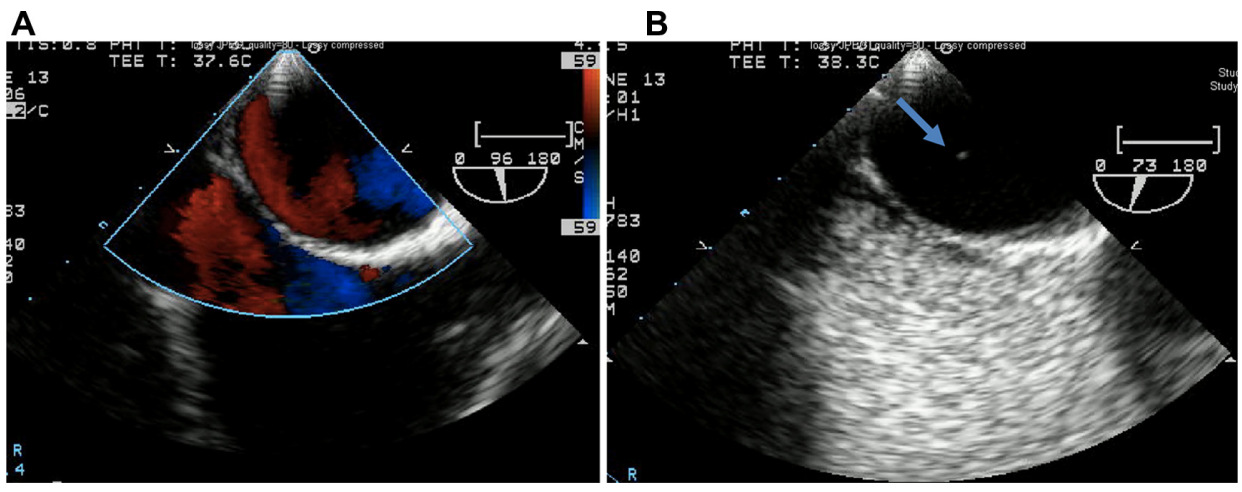

Figure 2 Echocardiogram TEE PFO.

Notes: TEE showed a very minor PFO only with a Valsalva maneuver. Doppler views did not demonstrate a PFO (A). During the Valsalva maneuver, a single bubble became apparent (blue arrow) (B). There was no aortic dissection.

Abbreviations: PFO, patent foramen ovale; TEE, transesophageal echocardiogram. 

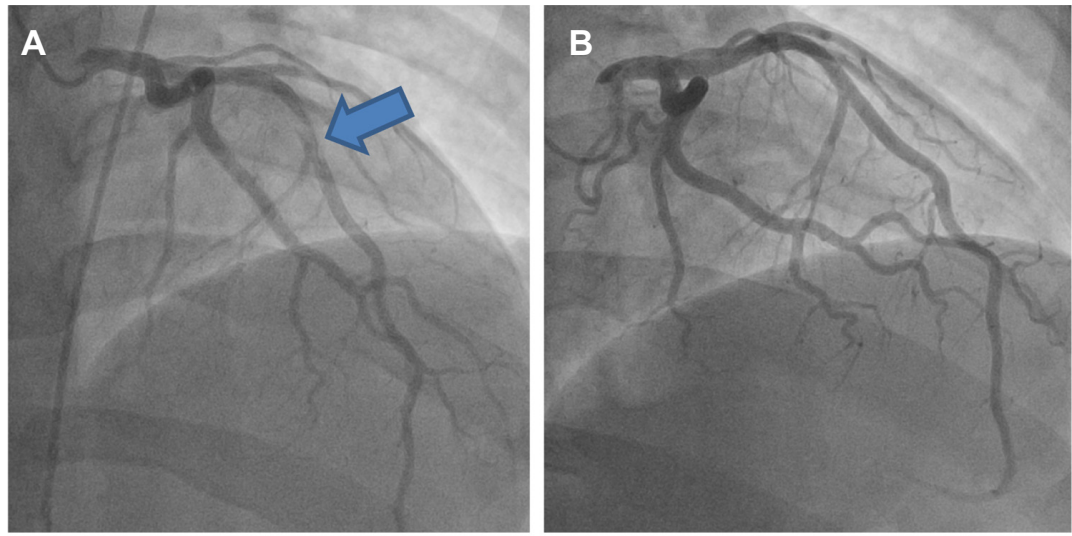

First event
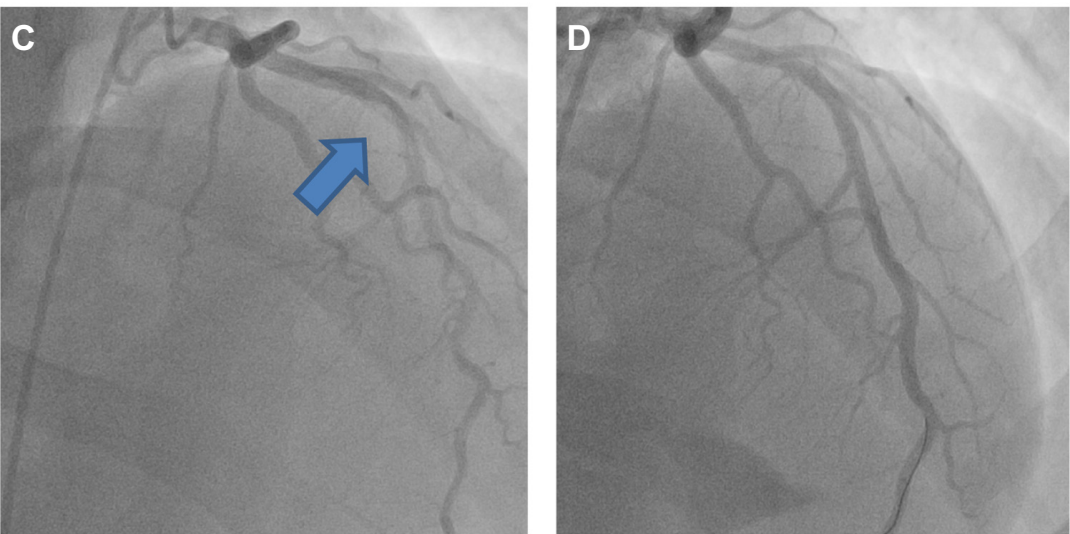

Second event

Figure 3 Left heart catheterization.

Note: (A) shows a thrombus in the proximal to mid LAD. (B) shows the dissolution of the thrombus. (C) shows recurrence of thrombus from the second cardiac event months later. (D) shows reperfusion of the vessel after stent placement. The coronary angiography shows a thrombus in the proximal to mid LAD (arrow) in otherwise normal coronary arteries.

Abbreviation: LAD, left anterior descending artery.
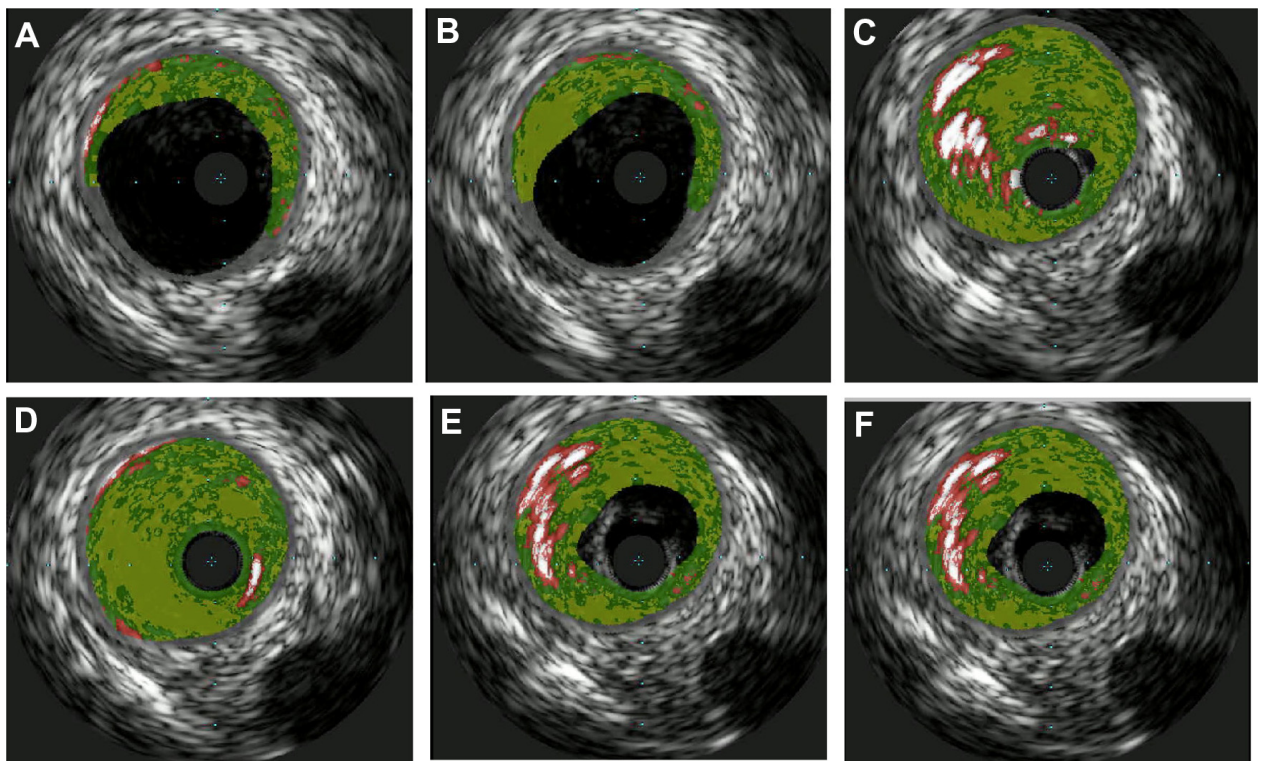

Figure 4A-F Coronary ultrasound showing vessel walls with mild plaque disease and thrombus lodged in vessel walls of LAD appreciated especially in (C) and (D). Note: The intravascular ultrasound of the LAD demonstrates mild plaque disease with thrombus lodged in vessel walls of the LAD.

Abbreviation: $L A D$, left anterior descending artery. 
Table 2 Hypercoagulability results

\begin{tabular}{|c|c|}
\hline Item and ref range & Result \\
\hline Factor VIII (60\%-I40\%) & $205 \%$ \\
\hline $\begin{array}{l}\text { Antiphospholipid Atb panel, cardiolipin Atb, } \\
\text { lupus anticoagulant, antiB2GPI Atb }\end{array}$ & wnl \\
\hline Protein S activity (60\%-165\%) & $98 \%$ \\
\hline Protein C activity $(60 \%-140 \%)$ & $137 \%$ \\
\hline APC resistance ( $2.0-4.9$ ratio) & 2.10 \\
\hline Homocysteine level $(4.0-12.0 \mu \mathrm{mol} / \mathrm{L})$ & 8.60 \\
\hline Factor II level (65\%-120\%) & $121 \%$ \\
\hline Factor V Leiden mutation & Negative \\
\hline Plasminogen activator inhibitor Atb (I.5-50.0 ng/mL) & 4.1 \\
\hline Prothrombin $20210 \mathrm{G}>\mathrm{A}$ mutation & Negative \\
\hline Antithrombin III activity (70\%-I20\%) & $77 \%$ \\
\hline Liver function test & wnl \\
\hline $\begin{array}{l}\text { Activated partial thromboplastin time APTT } \\
(25.0-35.0 \text { seconds) }\end{array}$ & 31.1 \\
\hline ANA $(<1: 40)$ & $<\mathrm{I}: 40$ \\
\hline $\operatorname{lgG}(59|-|, 540$ mg/dL) & 922 \\
\hline $\operatorname{lgA}(60-413 \mathrm{mg} / \mathrm{dL})$ & $17 \mid$ \\
\hline $\operatorname{lgM}(54-285$ mg/dL) & 45 \\
\hline Direct Coombs test & Negative \\
\hline LDH (98-192 IU/L) & 153 \\
\hline
\end{tabular}

Notes: 2cl9 for clopidogrel metabolization, ANA $<\mathrm{I}: 40$, cardiolipin $\mathrm{A} / \mathrm{M} / \mathrm{G}$, anti b2GPI IgA/M/G, phosphatide IgM/G, lupus anticoagulant, Direct Coombs C3/lgG, IgA/ $\mathrm{G} / \mathrm{M}$, plasminogen activator inhibitor $\mathrm{Ag}$, prothrombin 20210A, antithrombin iii, APC resistance, factor II, factor $\mathrm{V}$ Leiden mutation, homocysteine, protein $\mathrm{C}$ and $\mathrm{S}$ activity. Abbreviations: ref, reference; Atb, antibody; APC, activated protein C; ANA, antinuclear antibody; LDH, lactate dehydrogenase; lgG, immunoglobulin; wnl, within normal limits.

had a previous thrombus that had recurred at the same location. The rest of the coronary arteries were normal by angiography. Due to the PFO, a hypercoagulable workup was performed. A lower extremity ultrasound did not show any DVT. Results of laboratory studies showed elevated factor VIII activity at $205 \%$ (Table 2). A decision to put the patient on anticoagulation therapy was made in light of the likely arterial embolus versus paradoxical embolism. He was discharged home with aspirin (81 mg daily), prasugrel (10 $\mathrm{mg}$ daily), atorvastatin ( $80 \mathrm{mg}$ daily), and warfarin (5 mg daily with enoxaparin bridging). The ACE inhibitor was temporarily held because of mild acute kidney injury that was more likely a falsely elevated creatinine secondary to increased muscle mass. A beta blocker was stopped secondary to bradycardia.

\section{Discussion}

Factor VIII is a nonenzymatic plasma protein necessary for blood coagulation to proceed. Deficiency of factor VIII results in a condition named hemophilia A that affects $1 / 5,000$ males. The opposite condition, where there is too much factor VIII available, results in increased risk for thrombosis. Hemophilia A is inherited as an X-linked recessive disease expressed in males, with females as asymptomatic carriers. Factor VIII serves as a cofactor to enzyme 9a in the activation of factor X. Factor VIII must be activated before it can support factor IXa as an effective cofactor. The factor VIII protein contains over 2,300 amino acids and is approximately $330 \mathrm{kDa}$, preceded by a 19 residue hydrophobic signal peptide that is important for secretion. ${ }^{11}$

Just as there is a genetic basis to the absence of factor VIII, there is also a genetic component to having increased activity and levels. One study was able to localize high factor VIII levels to genes found on chromosome 5 and

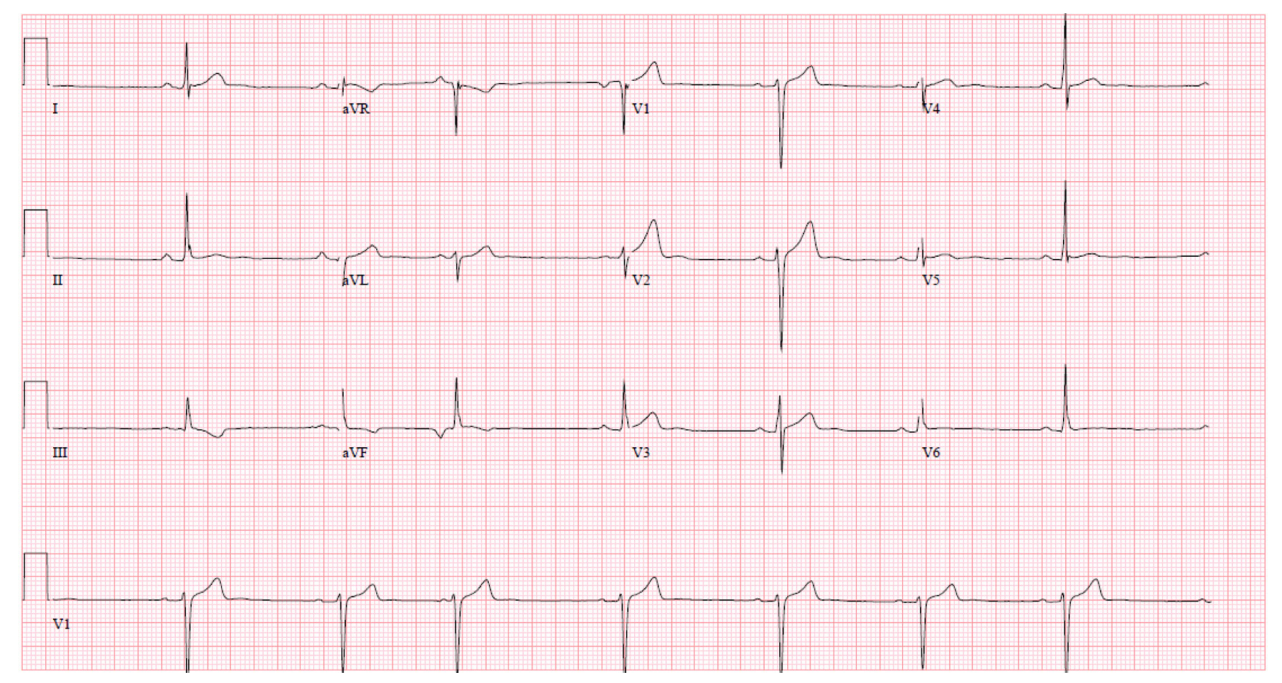

Figure 5 EKG second event.

Note: The EKG from the second event showed marked sinus bradycardia with PAC and existing T wave inversions in inferior leads.

Abbreviations: EKG, electrocardiogram; PAC, premature atrial complex. 
chromosome 11. ${ }^{12}$ Another quantitative trait locus was discovered on chromosome $18 .{ }^{13}$ Factor VIII is often found in a complex with von Willebrand factor (vWF) in the body. Hence, high factor VIII levels may also be caused by a rise in vWF levels; this could be from either increased synthesis or decreased clearance of $\mathrm{vWF}^{14}$ As further investigation continues, it will become interesting to determine if these chromosomal locations are involved in the regulation of vWF as well. The genetic basis for increased factor VIII levels is also greatly contingent on blood group types, as blood group non-O has higher levels of vWF and factor VIII than those with group O. ${ }^{15}$ Our patient has not pursued these genetic tests as he has other risk factors that can elevate factor VIII levels.

In addition, there are several acquired reasons for having high factor VIII levels, and some can be modified by lifestyle. Studies have found that a higher BMI positively correlated with higher factor VIII levels, as well as African descent that is associated with a $15 \%-18 \%$ increase of factor VIII levels above those of Caucasian descent. ${ }^{16}$ Our patient had a BMI of 39 and is of African descent; hence this is likely to increase his risk. Moreover, factor VIII levels increase with age, with an average rise of 5-6 IU/dL per decade. Exercise can transiently increase factor VIII levels, which are thought to be related to adrenalin and $\beta 2$ adrenoreceptor stimulation. ${ }^{17}$ Factor VIII levels are known to increase up to $300 \%$ in normal individuals during certain exercise. ${ }^{18}$ The weight lifting with extreme loads probably transiently increased the patient's factor VIII levels above his already high baseline. However, it is unclear whether the intensity of the exercise is correlated to the degree of factor VIII released. A rise in factor VIII can be seen in pregnancy, surgery, chronic inflammation, malignancy, liver disease, hyperthyroidism, intravascular hemolysis, and renal disease. ${ }^{19}$ Females generally have higher factor VIII levels for unknown reasons. ${ }^{20}$ Higher factor VIII levels were found in postmenopausal women compared to premenopausal. ${ }^{21}$ Furthermore, vasopressin enhances plasma factor VIII levels indirectly or directly via the v2 receptor. ${ }^{22}$ Thus, it is likely a good idea for postmenopausal women to remain euvolemic.

Factor VIII is known to increase a patient's risk for hypercoagulability. One study examined how factor VIII influences risk for MI among young Mexican patients with acute MI. It was again noted that younger patients $<45$ years accounted for only $5 \%-10 \%$ of acute MI cases. Twentyfive percent of patients had increased factor VIII compared with $8.8 \%$ of control subjects. Mean levels for patients and controls were $134 \mathrm{mg} / \mathrm{dL}$ versus $118 \mathrm{mg} / \mathrm{dL} .{ }^{23}$ Hence, even slightly elevated factor VIII levels contribute to MI, whereas higher levels are found in the more rare cases of young individuals having coronary events. Another report describes a 27-year-old female that had an MI and was found to have elevated factor VIII without any other hypercoagulability. There was a $90 \%$ stenosis of the proximal LAD. The level of her factor VIII was $3.03 \mathrm{IU} / \mathrm{mL}$; the normal range is $0.45-1.58 \mathrm{IU} / \mathrm{mL}^{24}$

The previously considered idiopathic cases of venous thromboembolism are now having correlations with elevated factor VIII levels. There was a dose-response relationship between subjects with factor VIII levels above $150 \%(150 \mathrm{IU} / \mathrm{dL})$ and an adjusted odds ratio for venous thromboembolism of $4.8 .^{13}$ It is also known that there is a $33 \%$ prevalence of factor VIII activity above $175 \%$ (90th percentile) in recurrent venous thromboembolism and is dose-related. ${ }^{25}$ Those above the 90th percentile for factor VIII had a 6.7-fold relative risk of recurrent events compared with lower levels. ${ }^{25}$ It is known that factor VIII levels above the normal $150 \mathrm{IU} / \mathrm{dL}$ can be found in $11 \%$ of the adult population. ${ }^{26}$ It is also concerning that there are additive effects to factor VIII and other hypercoagulable states. For instance, oral contraceptives in women with high factor VIII levels increased the risk of venous thromboembolism (VTE) greater than in women taking oral contraceptives alone. ${ }^{10}$

PFO is a common congenital cardiac anomaly that is estimated to be present in more than $25 \%$ of the general population. ${ }^{27}$ It is an independent risk factor for cerebrovascular events among young adults with cryptogenic stroke. ${ }^{28}$ Embolic events occurring through the PFO can affect all regions including the brain, extremities, and coronary circulation, depending on which branch of the aorta or sinus a thrombus may enter. Paradoxical coronary artery embolism causing MI with factor V Leiden thrombophilia in a young woman has been documented. ${ }^{9}$ There have also been associations with PFOs and MI for patients in hypercoagulable states, such as peripartum women. ${ }^{29} \mathrm{~A}$ girl as young as 8 years had a PFO combined with a heritable thrombophilia that resulted in MI. ${ }^{8}$ It is unclear where the initial thrombus in our patient developed - whether in the arterial circulation or the venous circulation with a translocation via a PFO. However, the venous Doppler of lower extremities was negative for DVT.

Our patient was found to have a RBBB on initial presentation. RBBB quite frequently occurs with $\mathrm{PFO}$ in healthy people and can even be used as a marker for PFO. ${ }^{30}$ PFO can be a problem for other recreational sports as well, such as recreational diving, which is becoming more and more popular, and also requires a Valsalva maneuver. 
Counseling should be provided to adults and adolescents with RBBB when they start high-risk sports or during qualifications for some types of employment.

One last point, we would like to make is that instrumentation poses its own risks to the development of atherosclerosis and plaque rupture, and that further investigation should be performed into preventing this remodeling effect. In previous experiments, substances such as the antioxidant hydrogen sulfide have been used as a means to reduce this remodeling effect. $^{31}$

\section{Conclusion}

We must never discount the cause of chest pain being MI in young adults as there are distinctive mechanisms by which these rare events can and do occur. The question then becomes how to prevent such rare cases as these. Strenuous exercise may possibly be a risk factor for coronary thrombosis because of transiently elevated factor VIII levels. It may be important to further risk stratify patients for physical activity using such factors as BMI, sex, descent, comorbidities, and hypercoagulability studies. As our genetic testing for hypercoagulability becomes both cheaper and more sensitive, it may be reasonable to put into action regular screening against these thrombotic disorders as a means of primary prevention before events occur. In light of the great prevalence of PFO and risks associated with fixing these genetic defects, fixing them should be discussed on an individual basis. Due to these existing limitations, an event tends to occur before this kind of extensive investigation is performed.

\section{Disclosure}

The authors report no conflicts of interest in this work.

\section{References}

1. Egred M, Viswanathan G, Davis GK. Myocardial infarction in young adults. Postgrad Med J. 2005;81(962):741-745.

2. Davidson L, Wilcox J, Kim D, Benton S, Fredi J, Vaughan D. Clinical features of precocious acute coronary syndrome. Am J Med. 2014;127(2):140-144.

3. Carbone I, Francone M, Galea N, Benedetti G, Frustaci A. Images in cardiology. Computed-tomography and magnetic resonance imaging assessment of traumatic left anterior descending coronary dissection causing acute myocardial infarction. J Am Coll Cardiol. 2011;57(2):e3.

4. Mastroroberto P, Di Mizio G, Colosimo F, Ricci P. Occlusion of left and right coronary arteries and coronary sinus following blunt chest trauma. J Forensic Sci. 2011;56(5):1349-1351.

5. Al-Aqeedi RF, Ali WM, Al-Ani F, Abdulrahman YS, Alnabti A. A blunt chest trauma causing left anterior descending artery dissection and acute myocardial infarction treated by deferred angioplasty. Heart Views. 2011;12(2):71-73.

6. Basso C, Maron BJ, Corrado D, Thiene G. Clinical profile of congenital coronary artery anomalies with origin from the wrong aortic sinus leading to sudden death in young competitive athletes. $\mathrm{J} \mathrm{Am} \mathrm{Coll} \mathrm{Cardiol}$. 2000;35(6):1493-1501.
7. Kandel DB, Murphy D, Karus D. Cocaine use in young adulthood: patterns of use and psychosocial correlates. NIDA Res Monogr. 1985;61:76-110.

8. Carano N, Agnetti A, Hagler DJ, Tchana B, Squarcia U, Bernasconi S. Acute myocardial infarction in a child: possible pathogenic role of patent foramen ovale associated with heritable thrombophilia. Pediatrics. 2004;114(2):e255-e258.

9. Croft AP, Khan JN, Chittari MV, Varma C. Paradoxical coronary artery embolism causing acute myocardial infarction in a young woman with factor V Leiden thrombophillia. $J R$ Coll Physicians Edinb. 2012;42(3):218-220.

10. Bloemenkamp KW, Helmerhorst FM, Rosendaal FR, Vandenbroucke JP. Venous thrombosis, oral contraceptives and high factor VIII levels. Thromb Haemost. 1999;82(3):1024-1027.

11. Rotblat F, O'Brien DP, O’Brien FJ, Goodall AH, Tuddenham EG. Purification of human factor VIII:C and its characterization by Western blotting using monoclonal antibodies. Biochemistry. 1985;24(16): 4294-4300.

12. Berger M, Mattheisen M, Kulle B, et al. High factor VIII levels in venous thromboembolism show linkage to imprinted loci on chromosomes 5 and 11. Blood. 2005;105(2):638-644.

13. Koster T, Blann AD, Briët E, Vandenbroucke JP, Rosendaal FR. Role of clotting factor VIII in effect of von Willebrand factor on occurrence of deep-vein thrombosis. Lancet. 1995;345(8943):152-155.

14. Kamphuisen PW, Eikenboom JC, Bertina RM. Elevated factor VIII levels and the risk of thrombosis. Arterioscler Thromb Vasc Biol. 2001;21(5):731-738.

15. Jeremic M, Weisert $\mathrm{O}$, Gedde-Dahl TW. Factor VIII (AHG) levels in 1016 regular blood donors. The effects of age, sex, and ABO blood groups. Scand J Clin Lab Invest. 1976;36(5):461-466.

16. Conlan MG, Folsom AR, Finch A, et al. Associations of factor VIII and von Willebrand factor with age, race, sex, and risk factors for atherosclerosis. The Atherosclerosis Risk in Communities (ARIC) Study. Thromb Haemost. 1993;70(3):380-385.

17. Small M, Tweddel AC, Rankin AC, Lowe GD, Prentice CR, Forbes CD. Blood coagulation and platelet function following maximal exercise: effects of beta-adrenoceptor blockade. Haemostasis. 1984;14(3): $262-268$.

18. Rock G, Tittley P, Pipe A. Coagulation factor changes following endurance exercise. Clin J Sport Med. 1997;7(2):94-99.

19. Bloom AL. The biosynthesis of factor VIII. Clin Haematol. 1979;8(1):53-77.

20. Wells PS, Langlois NJ, Webster MA, Jaffey J, Anderson JA. Elevated factor VIII is a risk factor for idiopathic venous thromboembolism in Canada - is it necessary to define a new upper reference range for factor VIII? Thromb Haemost. 2005;93(5);842-846.

21. Balleisen L, Assmann G, Bailey J, Epping PH, Schulte H, van de Loo J. Epidemiological study on factor VII, factor VIII and fibrinogen in an industrial population - II. Baseline data on the relation to blood pressure, blood glucose, uric acid, and lipid fractions. Thromb Haemost. 1985;54(3):721-723.

22. Kaufmann JE, Oksche A, Wollheim CB, Günther G, Rosenthal W, Vischer UM. Vasopressin-induced von Willebrand factor secretion from endothelial cells involves V2 receptors and cAMP. $J$ Clin Invest. 2000;106(1):107-116.

23. Majluf-Cruz A, Moreno-Hernández M, Martínez-Esquivel N, et al [Factor VIII activity among young Mexican patients with acute myocardial infarction]. Gac Med Mex. 2008;144(3):199-206. Spanish.

24. Gorog DA, Rakhit R, Parums D, Laffan M, Davies GJ. Raised factor VIII is associated with coronary thrombotic events. Heart. 1998;80(4):415-417.

25. Kraaijenhagen RA, in't Anker PS, Koopman MM, et al. High plasma concentration of factor VIIIc is a major risk factor for venous thromboembolism. Thromb Haemost. 2000;83(1):5-9.

26. Bénard E, Lafuma A, Ravaud P. [Epidemiology of venous thromboembolic disease]. Presse Med. 2005;34(6):415-419. French. 
27. Hagen PT, Scholz DG, Edwards WD. Incidence and size of patent foramen ovale during the first 10 decades of life: an autopsy study of 965 normal hearts. Mayo Clin Proc. 1984;59(1):17-20.

28. Webster MW, Chancellor AM, Smith HJ. Patent foramen ovale in young stroke patients. Lancet. 1988;2(8601):11-12.

29. Ramineni R, Daniel GK. Association of a patent foramen ovale with myocardial infarction and pulmonary emboli in a peripartum woman. Am J Med Sci. 2010;340(4):326-328.
30. Bakalli A, Koçinaj D, Georgievska-Ismail L, Bekteshi T, Pllana E, Sejdiu B. Right bundle branch block as a marker for interatrial septal abnormalities. Cardiol Young. 2012;22(1):18-25.

31. Vacek TP, Gillespie W, Tyagi N, Vacek JC, Tyagi SC. Hydrogen sulfide protects against vascular remodeling from endothelial damage. Amino Acids. 2010;39(5):1161-1169.

\section{Publish your work in this journal}

The International Medical Case Reports Journal is an international, peer-reviewed open-access journal publishing original case reports from all medical specialties. Previously unpublished medical posters are also accepted relating to any area of clinical or preclinical science. Submissions should not normally exceed 2,000 words or
4 published pages including figures, diagrams and references. The manuscript management system is completely online and includes a very quick and fair peer-review system, which is all easy to use. Visit http://www.dovepress.com/testimonials.php to read real quotes from published authors.

Submit your manuscript here: http://www.dovepress.com/international-medical-case-reports-journal-journal 